\title{
En el primer aniversario de la muerte de José Luis L. Aranguren
}

El 17 de abril de 1996, hace ahora aproximadamente un año, fallecia José Luis L. Aranguren. Presidente del Patronato del Instituto de Filosofia del CSIC, Aranguren fue además el auténtico mentor de Isegoría, en cuyo primer número nos obsequiaba con una "Epistola moral (Reflexiones sobre el "deber ser" de una revista de filosofia moral y política)», invitándonos a "no encerrarnos en una sola filosofia", sino a kmostrarnos abiertos e interesados en todas", pero siempre, eso sí, desde una «actitud crítica», que para él venía sin más a coincidir con «la actitud moral.. a saber, aquella que afirma en el ser humano su dimensión moral... y, más aún, la pertinencia de ser definido como un ser morals. Cuantos en esta revista trabajamos queremos hoy expresar, con este número especial dedicado a su memoria, nuestro profundo agradecimiento a José Luis L. Aranguren por el apoyo y el consejo que generosa e invariablemente nos brindó.

Pero, por más que esta revista pueda considerarse suya, nada más lejos del ánimo que nos inspira que considerar unuestro» a Aranguren. Aranguren, tenido con justicia como el padre de la Ética contemporánea en España por la práctica totalidad de la comunidad filosófica nacional, es patrimonio de esta última, de suerte que nadie dentro de ella podría reivindicar su herencia en exclusiva. Así lo han entendido sus diversos representantes, como lo acreditan, por citar sólo tres botones de muestra, las emotivas necrologías con que -adelantándose a este número de nuestra revista - le homenajean publicaciones como Télos (Universidad de Santiago), Disenso (Revista Canaria de Análisis y Opinión) o Contrastes (Universidad de Málaga). Aun cuando en la obra de Unamuno, de Ortega o de Zubiri no falten, como de hecho no faltan, preocupaciones de índole ética, la Ética no había sido expresamente tematizada en nuestra tradición filosófica reciente hasta que Aranguren lo hizo en la estela de aquellos grandes hitos de la misma, habiéndole correspondido por añadidura la misión de abrir la investigación ética en España a la que se venía haciendo en el resto del mundo. De ahi que sin exageración pueda afirmarse que, en el cultivo de dicha disciplina en nuestro país, es obligado distinguir entre un «antes» y un «después» de Aranguren.

Para confirmar semejante aserto bastaria con repasar la impresionante lista de colaboradores al volumen Ética día tras día (Homenaje al Profesor Aranguren en su ochenta cumpleaños), patrocinado en 1991 por el Instituto de Filosofia, la mayoría de chays colaboraciones, sin embargo, no versaban expresamente -como es frecuente en este tipo de homenajes- sobre el propio Aranguren.

Al análisis del pensamiento de Aranguren se destina, en cambio, el grueso del presente número de nuestra revista. En él es estudiado, ante todo, su pensamiento ético, pero asimismo su contribución en campos tan diversos como la filosofia social y politica, la antropología moral o la filosofia de la religión. Naturalmente, 
no podía faltar el examen de su concepción del «oficio del intelectuals, que Aranguren gustaba de asociar al «oficio del moralista», cimentando sobre él una teoría y una praxis de la filosofía como "crónica moral de nuestro tiempo" y poniéndolo al servicio de la defensa de la libertad y la justicia, tanto en los sombrios tiempos de la dictadura como en los más esperanzados pero incientos de una democracia todavia, y acaso permanentemente, en trance de consolidación. Y se pasa igualmente revista a otras facetas menos divulgadas del quehacer arangureniano, como su dedicación a la crítica filosófica de la literatura. Finalmente, el análisis concluye con un repaso de la bibliografía de y sobre Aranguren, incluida una minuciosa recensión de la edición completa de sus obras.

Nuestro número especial dedicado a la memoria de Aranguren quedaría incompleto sin atender a la excepcional calidad humana de su personalidad. $A$ los testimonios de familiares y amigos que lo abren se añaden las palabras pronunciadas con ocasión de su funeral por José Gómez Caffarena, cuyas Quintas Conferencias Aranguren -asimismo recogidas en estas páginas - constituyen su particular homenaje al maestro de todos. El número se cierra con la para nosotros también tristísima noticia de la muerte de José María Valverde, quien no dudara un día en abandonar su cátedra por solidaridad con Aranguren y nos ha abandonado ahora, esta vez para siempre, pocos meses después de hacerlo él. 